\title{
Origins of circulating endothelial cells and endothelial outgrowth from blood
}

\author{
Yi Lin, Daniel J. Weisdorf, Anna Solovey, and Robert P. Hebbel \\ Department of Medicine, Box 480 UMHC, 420 Delaware Street SE, University of Minnesota, \\ Minneapolis, Minnesota 55455, USA
}

Address correspondence to: Robert P. Hebbel, Department of Medicine, Box 480 UMHC, 420 Delaware Street SE, University of Minnesota, Minneapolis, Minnesota 55455, USA.

Phone: (612) 624-6104; Fax: (612) 625-6919; E-mail: hebbe001@tc.umn.edu.

Received for publication August 5, 1999, and accepted in revised form November 10, 1999.

\begin{abstract}
Normal adults have a small number of circulating endothelial cells (CEC) in peripheral blood, and endothelial outgrowth has been observed from cultures of blood. In this study we seek insight into the origins of CEC and endothelial outgrowth from cultures of blood. Fluorescence in situ hybridization analysis of blood samples from bone marrow transplant recipients who had received gender-mismatched transplants 5-20 months earlier showed that most CEC in fresh blood had recipient genotype. Endothelial outgrowth from the same blood samples after 9 days in culture (5fold expansion) was still predominantly of the recipient genotype. In contrast, endothelial outgrowth after $\sim 1$ month (102-fold expansion) was mostly of donor genotype. Thus, recipient-genotype endothelial cells expanded only 20 -fold over this period, whereas donor-genotype endothelial cells expanded $\sim 1000$-fold. These data suggest that most CEC in fresh blood originate from vessel walls and have limited growth capability. Conversely, the data indicate that outgrowth of endothelial cells from cultures of blood is mostly derived from transplantable marrow-derived cells. Because these cells have more delayed outgrowth but a greater proliferative rate, our data suggest that they are derived from circulating angioblasts.
\end{abstract}

J. Clin. Invest. 105:71-77 (2000).

\section{Introduction}

The endothelium, a vital component of the vascular wall, comprises $10^{13}$ endothelial cells and covers approximately $7 \mathrm{~m}^{2}$ in an average adult (1). These endothelial cells provide the physical interface between blood and surrounding tissue, regulate nutrient and blood component traffic, and participate in many physiologic events such as hemostasis, inflammation, and angiogenesis (1-4). The identification and characterization of endothelial progenitor cells have been elusive tasks.

Nonhematological cells were reported as early as 1934 in the blood of certain cancer patients (5). However, only recently have more refined isolation procedures and immunohistochemical examinations proved that at least some circulating nonhematological cells are endothelial in identity (6-8). Since then, circulating endothelial cells (CEC) have been described in several pathologic conditions that have in common the presence of vascular injury (9-17). Our recent enumeration of CEC documented that normal adults have $2.6 \pm 1.6$ CEC per milliliter of peripheral blood (9). The majority of these CEC are quiescent, and at least half are microvascular as defined by CD36 positivity (9). We found that the number of CEC was increased in patients with sickle cell anemia and that these cells exhibited an activated phenotype with abnormal expression of proadhesive and procoagulant molecules $(9,18)$. The phenotype of these CEC is postulated to reflect the status of the endothelium in situ $(9,18,19)$, but whether CEC themselves are derived from vessel walls is not known.

Besides the presence of identifiable CEC in samples of fresh blood, there is also an evident outgrowth of endothelial cells when peripheral blood is cultured. We observed that some CEC are viable in culture (9), and Asahara et al. (20) and Shi et al. (21) observed endothelial outgrowth from CD34-enriched peripheral blood cells. They interpreted this endothelial outgrowth as constituting evidence for the presence of circulating angioblasts. However, the presence of CEC in fresh blood $(9,18)$ makes this an uncertain assumption. Differentiated endothelial cells clearly have proliferative potential, as evidenced by the routine use of vessel segments as sources for endothelial culture in vitro (22-23). Therefore, the mere occurrence of outgrowth is insufficient evidence to confirm the presence of an angioblast. The goal of this study was to gain additional insight into this problem by examining the relationship between the CEC present in peripheral blood and endothelial outgrowth obtained from cultures of blood.

\section{Methods}

Study subjects. We used 7 blood samples from 4 subjects who had given informed consent to participate in this study (Table 1). All subjects had received a bone marrow transplantation from a gender-mismatched 


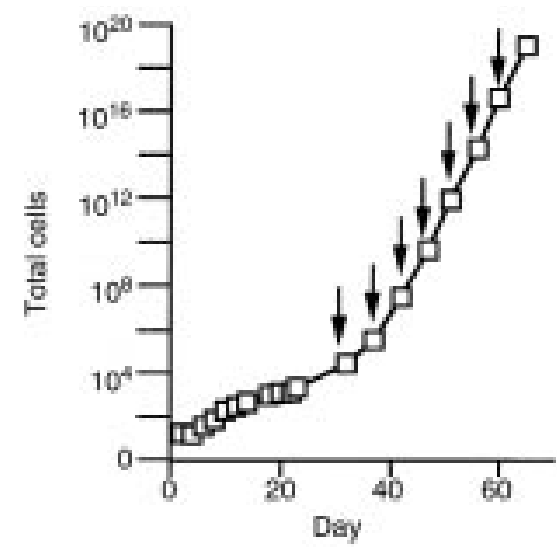

Figure 1

Endothelial expansion from buffy coat mononuclear cells of normal blood. On day 2 and for subsequent passages (indicated by arrows), the number of endothelial cells was confirmed by staining for $\mathrm{P} 1 \mathrm{H} 12$ and VWF, and that number was consistent with the cell count by morphology. All data points plotted as mean $\pm \mathrm{SD}$ ( $n=5$ for culture up to passage $6 ; n=4$ for subsequent passages).

donor 5-20 months earlier. At the time of study, all subjects were healthy: none were taking immunosuppressive drugs, and none had active infections or graft-versus-host disease.

Blood sample. Fresh blood was collected from volunteer donors by venipuncture and anticoagulated with either heparin or buffered sodium citrate. The anticoagulated blood was diluted 1:2 with HBSS containing $1 \mathrm{mM}$ EDTA and $0.5 \%$ BSA.

CEC enrichment. We used P1H12-conjugated beads to enrich CEC from peripheral blood based on the previous findings that monocytes do not express P1H12 (9) and that P1H12-positive blood cells were uniformly positive for von Willebrand factor (vWF) and thrombomodulin (9). Monoclonal murine antibody P1H12 (9) was conjugated to M-450 immunomagnetic beads (Dynal Inc., Success Lake, New York, USA) at $1.5 \mu \mathrm{g}$ $\mathrm{mAb}$ per $10^{7}$ beads based on manufacturer's instructions. CEC were enriched from diluted blood, as described (9). Briefly, $1 \mu \mathrm{L}$ of beads was used per milli- liter of original amount of whole blood. Cells were incubated with beads for 45 minutes at $4^{\circ} \mathrm{C}$ with bidirectional shaking and enriched using a magnetic separator. Bead-enriched cells were then cytospun onto slides for analysis.

Buffy coat cell preparation. Buffy coat mononuclear cells were obtained from diluted blood using Histopaque1077 (Sigma Chemical Co., St. Louis, Missouri, USA) following manufacturer's protocol. These cells were washed 3 times at $250 \mathrm{~g}$ for 10 minutes using a culture medium consisting of MCDB 131 supplemented with $1 \mu \mathrm{g} / \mathrm{mL}$ hydrocortisone acetate, $0.5 \mathrm{mM}$ dibutryl cAMP, $1.6 \mathrm{mM}$ L-glutamine, 100 units $/ \mathrm{mL}$ penicillin, 100 units $/ \mathrm{mL}$ streptomycin, $0.25 \mathrm{mg} / \mathrm{mL}$ amphotericin $\mathrm{B}, 0.004 \%$ heparin, and $10 \mathrm{ng} / \mathrm{mL}$ VEGF (23).

Endothelial culture from peripheral blood. Buffy coat mononuclear cells from 50 or $100 \mathrm{~mL}$ of blood were resuspended in EGM-2 medium (Clonetics Inc., San Diego, California, USA) without further cell subpopulation enrichment procedures and placed into 1 well of a 6-well plate coated with type I collagen (Becton Dickinson Microbiology Systems, Sparks, Maryland, USA). The plate was incubated at $37^{\circ} \mathrm{C}$ in a humidified environment with $5 \% \mathrm{CO}_{2}$. Culture medium was changed daily. After 24 hours, unattached cells and debris were removed by washing with medium. This procedure leaves $19 \pm 9$ attached endothelial cells, as identified by morphology and staining with anti-endothelial monoclonal antibody P1H12 (9), plus 100-200 other mononuclear cells. These mononuclear cells appeared to be monocytes by morphology and died out within the first 2-3 weeks of culture.

Cells were first passed at 4 weeks after 100-fold expansion. We used $0.025 \%$ trypsin (GIBCO BRL, Grand Island, New York, USA) for passing cells and tissue culture plates coated with $50 \mu \mathrm{g} / \mathrm{mL}$ of fibronectin as substrate. If allowed to continue growing, cells in this culture system expand exponentially and reach $10^{19}$ cells by 6 weeks. Figure 1 shows the growth curve we observed using this method on 5 normal control samples. Growth for post-transplant recipients is indistinguishable from control samples (data not shown).

Table 1

Study subjects

\begin{tabular}{|c|c|c|c|c|c|c|c|}
\hline \multicolumn{4}{|c|}{ BMT recipient } & \multicolumn{3}{|c|}{ BMT donor } & \multirow{2}{*}{$\begin{array}{l}\text { Interval from transplant } \\
\text { to study (months) }\end{array}$} \\
\hline Subject & Age & Sex & Diagnosis & Relationship & Age & Cell source & \\
\hline A & 49 & M & Non-Hodgkin's lymphoma & Sibling & 48 & Peripheral blood & 5 \\
\hline B & 37 & $\mathrm{~F}$ & Acute myeloid leukemia & Sibling & 38 & Bone marrow & 6 \\
\hline C & 32 & M & Chronic myeloid leukemia & Sibling & 15 & Bone marrow & 6 \\
\hline D & 43 & M & Acute lymphoid leukemia & Unrelated & 50 & Bone marrow & 11 \\
\hline D & & & & & & & 14 \\
\hline D & & & & & & & 17 \\
\hline D & & & & & & & 20 \\
\hline
\end{tabular}

BMT, bone marrow transplant. 


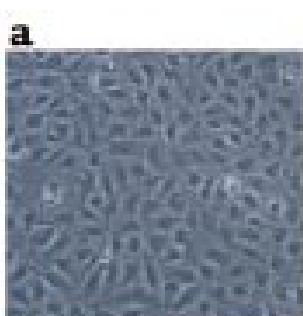

Oulgrowth coll

morphology b

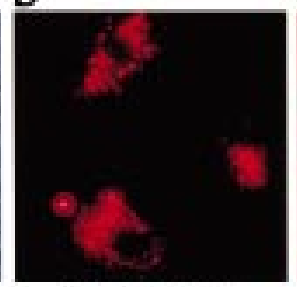

Acetylated-LDL

uptake

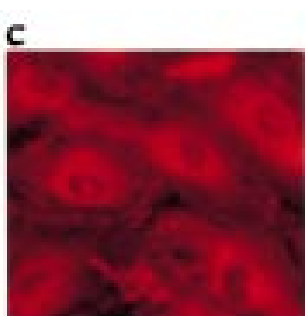

WWF

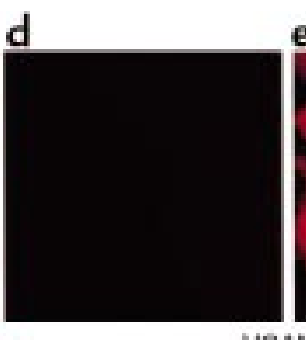

No simulation

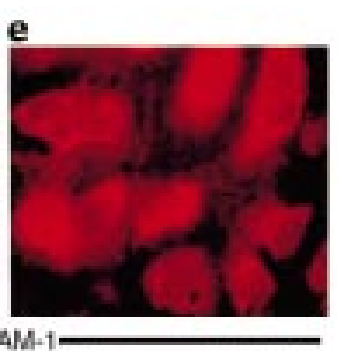

Exposure to IL-1

Figure 2

Outgrowth endothelial cell morphology and phenotype. Outgrowth cells have typical endothelial morphology (a). The remaining parts (b-e) show, as labeled at the bottom of each, constitutive and activated phenotype by immunofluorescent staining. Outgrowth endothelial cells incorporated acetylated LDL and were positive for VWF. They were negative for VCAM-1 but expressed it upon stimulation.

However, for the present study of endothelial outgrowth from blood obtained from bone marrow transplant recipients, we chose about 4 weeks as the longest time point in the analysis. This time point allowed sufficient expansion to ensure that the cells we examined were, indeed, derived from proliferation in culture. Yet, it is limited enough in degree of expansion to allow all of the outgrowth cells to be examined for genotype.

Phenotype characterization. We used indirect immunofluorescence to define endothelial cell phenotype. CEC from fresh blood and outgrowth cells from cultures of blood were rinsed twice with HBSS and fixed immediately with $4 \%$ paraformaldehyde for 10 minutes at $37^{\circ} \mathrm{C}$. Detection of vWF and flk-1 required permeabilization by 10 minutes' incubation with $0.1 \%$ Triton X-100. We used primary antibodies at working concentrations of $2-20 \mu \mathrm{g} / \mathrm{mL}$ against human $\mathrm{vWF}$ and CD51 (Sigma), CD34 and CD36 (Immunotech Inc., Westbrook, Maine, USA), flk-1, CD14, and VEcadherin (Santa Cruz Biotechnology Inc., Santa Cruz, California, USA), P1H12 (9), thrombomodulin (kindly provided by A. Slungaard, University of Minnesota), PECAM-1 (Novacastra Laboratories Ltd., Burlingame, California, USA), VCAM-1 and ICAM-1 (Southern Biotech Assoc., Birmingham, Alabama, USA), and tissue factor (kindly provided by R. Bach, University of Minnesota). As a positive control, we used antibody to $\beta 2$-microglobulin (Sigma). As a negative control, we used same-species, same-isotype irrelevant antibodies (Sigma). Binding of primary antibodies against vWF, thrombomodulin, and flk-1, was detected using 1:100 dilution of stock rhodamine-conjugated goat anti-rabbit IgG (Jackson ImmunoResearch Laboratories Inc., West Grove, Pennsylvania, USA). Binding of other primary antibodies was detected using $7 \mu \mathrm{g} / \mathrm{mL}$ of lissamine rhodamine-conjugated goat anti-mouse IgG (Jackson ImmunoResearch Laboratories Inc.). All primary and secondary antibodies were diluted in HBSS plus 3\% BSA and 0.2\% Tween-20. Fluoromount G (Southern Biotechnology Assoc.) was added to the slides after staining. The cells were viewed by fluorescence microscopy using standard rhodamine excitation/emission filter combinations.
To detect acetylated-LDL uptake, cells were incubated with $10 \mu \mathrm{g} / \mathrm{mL}$ of acetylated LDL (Molecular Probes, Eugene, Oregon, USA) at $37^{\circ} \mathrm{C}$ for 4 hours. To deliberately activate endothelial cells, they were incubated at $37^{\circ} \mathrm{C}$ for 4 hours with either $10 \mathrm{ng} / \mathrm{mL}$ of IL- 1 for stimulation of VCAM- 1 and ICAM-1, or $10 \mathrm{ng} / \mathrm{mL}$ of LPS for tissue factor stimulation.

To analyze cell phenotype using flow cytometry, cells in suspension were washed twice with PBS containing $0.5 \%$ BSA and fixed in $2 \%$ paraformaldehyde for 10 minutes at $37^{\circ} \mathrm{C}$ and 10 minutes at $4^{\circ} \mathrm{C}$. For detection of vWF and flk-1 expressions, cells were permeabilized with 9:1 methanol/PBS for 20 minutes at $-20^{\circ} \mathrm{C}$. Then the cells in suspension were labeled with the same antibodies as described above and resuspended in 2\% paraformaldehyde for analysis. Flow cytometry analysis was performed in a FACScalibur flow cytometer (Becton Dickinson Immunocytometry Systems, San Jose, California, USA) using FL1 channel for detection of fluorescein signal and FL2 channel for detection of rhodamine signal. Cells $\left(10^{4}\right)$ were collected from each sample and analyzed using CELLQuest software (Becton Dickinson).

To detect Weibel-Palade bodies inside outgrowth endothelial cells, cells were grown on coverslips and fixed in $1.25 \%$ glutaraldehyde for 15 minutes at $37^{\circ} \mathrm{C}$ and $2.5 \%$ glutaraldehyde overnight at $37^{\circ} \mathrm{C}$. The cells were then prepared for and examined by transmission electron microscopy.

Fluorescent in situ bybridization. Endothelial cells were cytospun onto a microscope slide and fixed with cold 1:1 methanol and acetone mixture for 10 minutes. Fluorescent in situ hybridization (FISH) analysis for the $\mathrm{X}$ and Y chromosomes of these cells was conducted following manufacturer's protocol (Boehringer Mannheim Biochemicals, Indianapolis, Indiana, USA). We used $1 \mu \mathrm{g} / \mathrm{mL}$ of digoxigenin-labeled human chromosome Y-specific DNA probe and $1 \mu \mathrm{g} / \mathrm{mL}$ of fluorescein-labeled human chromosome X-specific DNA probe (Boehringer-Mannheim). For the detection of the $Y$ chromosome, $20 \mu \mathrm{g} / \mathrm{mL}$ of anti-digoxenin-rhodamine Fab fragment (Boehringer-Mannheim) was used. Finally, cells were labeled with antibody P1H12, as described above, followed by $10 \mu \mathrm{g} / \mathrm{mL}$ of AMCAS 

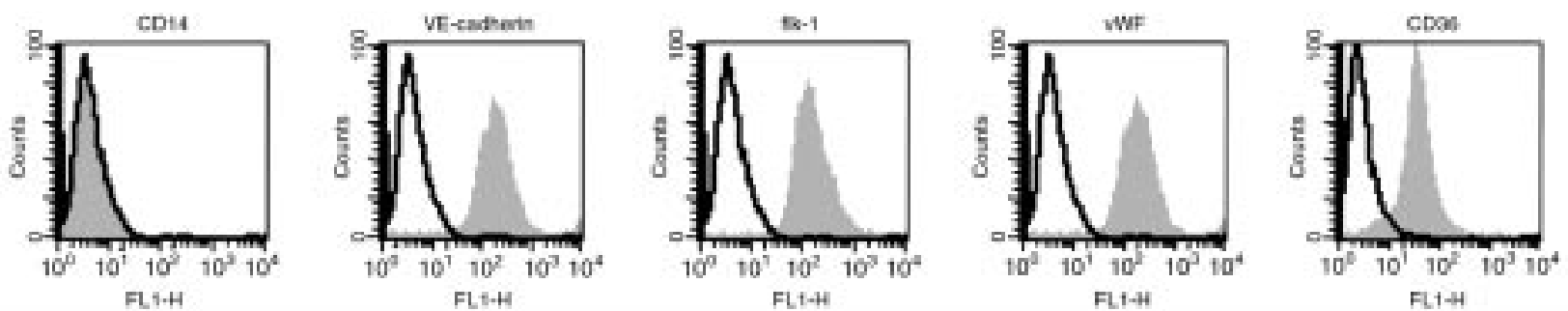

Figure 3

Flow cytometry analysis of outgrowth endothelial cell phenotype. In each graph, the black line outlines the region of fluorescent intensity for cells labeled with negative control antibody. The filled region identifies cells labeled with antibody for the expression marker indicated above each graph. Outgrowth cells are negative for CD14 (monocyte marker) and positive for flk-1, vWF, CD36, and the endothelial-specific marker VE-cadherin.

blue-conjugated secondary antibody. We scored only those cells for which 2 fluorescent spots could be seen clearly. In preliminary experiments, analysis of primary microvascular endothelial cells and outgrowth endothelial cells from blood of normal untransplanted blood donors showed $100 \%$ accuracy in genotype detection using this method.

\section{Results}

Phenotype of outgrowth endothelial cells. The outgrowth endothelial cells from blood exhibited the typical "cobblestone" morphology of endothelial cells (Figure 2). The outgrowth cells incorporated acetylated LDL and were uniformly positive for VWF (Figure 2). They were also uniformly positive for endothelial markers such as P1H12, thrombomodulin, flk-1, VE-cadherin (which is endothelial specific), PECAM-1, CD34, CD36, and integrin $\alpha_{v}$ (data not shown). They were uniformly negative for monocyte marker CD14 (Figure 3). We confirmed the homogeneity of outgrowth endothelial cell expression using flow cytometry as shown in Figure 3 for CD14 (negative), and for VE-cadherin, flk-1, vWF, and CD36. In addition, transmission electron microscopy analysis revealed the presence of Weibel-Palade bodies inside outgrowth endothelial cells (data not shown). This combined expression of multiple endothelial markers unequivocally confirmed the cells' endothelial identity. The phenotype of the outgrowth endothelial cells remains the same from week 4 through all subsequent passages.

The expression of CD36 on these cells argues that they are microvascular in phenotype (24). The outgrowth cells weakly expressed ICAM-1, but they did not constitutively express endothelial activation markers such as VCAM-1 and tissue factor. However, IL-1 or LPS stimulated the expression of VCAM-1 and tissue factor and increased the expression of ICAM- 1 in these cells (shown in Figure 2 for VCAM-1). Thus, the outgrowth endothelial cells have a quiescent microvascular phenotype, and they have the functional capacity to respond to physiologically relevant stimuli.

$C E C$ and endothelial outgrowth from bone marrow transplant recipients. To determine the origins of fresh CEC and outgrowth endothelial cells, we identified their genotype (XX or XY) in 4 adults who had previously undergone marrow transplantation of hematopoietic stem cells from gender-mismatched donors. We identified genotype of P1H12-positive cells using FISH for the X and $Y$ chromosomes (Figure 4). All P1H12-positive blood cells are positive for multiple endothelial markers (9). At the time of study, all recipients' marrow and/or peripheral blood were $100 \%$ donor genotype as determined by restriction fragment length polymorphism (RFLP) and/or cytogenetic analysis. Each of the 7 blood samples was divided into 2 aliquots: one for analysis of fresh CEC enriched by immunomagnetic beads and the other for buffy coat culture to obtain endothelial outgrowth.

Fluorescent microscopic examination of CEC revealed that $95 \pm 6 \%(n=4)$ of the CEC in fresh blood had the recipient genotype. Conversely, only $5 \pm 6 \%$ ( $n$ $=4$ ) of the CEC in blood had donor genotype. These results suggest that the predominant population of CEC in fresh blood is derived from vessel walls. (For these and the following data, the 4 sample values from subject $\mathrm{D}$ are averaged and taken as a single data point.)

The outgrowth endothelial cells from these same blood samples were examined in contemporaneous cultures at 2 different time points, 9 days and $27 \pm 4$ days in culture. All outgrowth cells had the same phenotype as described above. The total expansion of the outgrowth cells reached $5.4 \pm 2.5$-fold $(n=4)$ by 9 days, and it reached $102 \pm 28$-fold by $27 \pm 4$ days $(n=4)$.

As the cells expanded in culture, the proportion of outgrowth cells having recipient genotype declined from $95 \pm 6 \%$ at day $0(n=4)$, to $82.5 \%$ by day $9(n=2)$, and to $17 \pm 4 \%$ by day $27 \pm 4(n=4)$ (Figure 5). By combining the quantification of cell growth and percentage of each genotype, we calculated that recipient genotype endothelial cells expanded by only $17 \pm 9$-fold over 4 weeks. In striking contrast, over the same time period there was a somewhat delayed but much more exuberant 1,023 \pm 476 -fold expansion of donor genotype endothelial cells (Figure 5).

Despite the differences in time between transplant and study, the 4 samples from subject $D$ all behaved the same in culture (data not shown). The percentage of his endothelial cells having the recipient genotype for the sample at 11 months after transplant declined from $100 \%$ at day 0 to only $12.7 \%$ by $27 \pm 4$ days. Similarly, the percentage of his endothelial cells having recipient 
genotype for the sample at 20 months after transplant also declined from $100 \%$ at day 0 to $7.5 \%$ by $27 \pm 4$ days. In fact, all 7 samples yielded similar results regardless of the interval between transplant and study.

The sample from subject $A$, who received stem cells that had been harvested from blood rather than marrow, behaved just like the samples from the other subjects. There was also no detectable growth difference between samples from subject $C$ who received a transplant from a much younger donor, from subject $\mathrm{D}$ who received a transplant from an older donor, or from the other 2 samples in which the donor and recipient ages were very similar. Thus, cell outgrowth rates were not affected by transplant donor source or age.

\section{Discussion}

Examining recipients of gender-mismatched marrow transplants, we found that the predominant population (95\%) of CEC detectable in fresh peripheral blood had recipient genotype. Remarkably, peripheral blood also contained a small number of CEC (5\%) having donor genotype, indicating that they either were, or were derived from, transplanted cells. Genotype analysis of buffy coat cultures from these subjects showed an outgrowth of endothelial cells of both donor and recipient genotypes. However, endothelial cells having recipient genotype had expanded only $17 \pm 9$-fold after $27 \pm 4$ days in culture, whereas cells having genotype of the transplant donor showed a somewhat delayed growth but expanded fully $1023 \pm 476$-fold

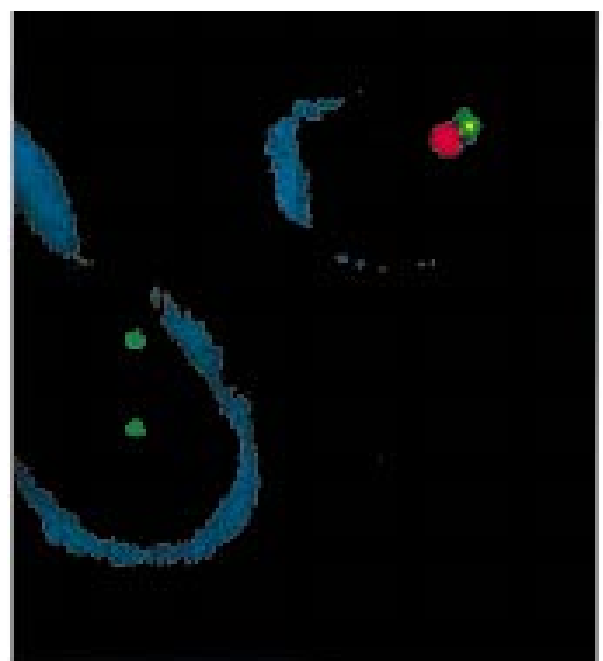

\section{Figure 4}

FISH for endothelial genotype. Cells were double-labeled for endothelial phenotype and gender genotype. Cell surface staining for $\mathrm{P} 1 \mathrm{H} 12$, shown here in blue, identified the cells as endothelial (9). A rhodamine-conjugated probe was used to identify $Y$ chromosomes; a FITC-conjugated probe was used to identify $X$ chromosomes. This illustration, using blood from subject $D$, shows 1 endothelial cell in the upper-right corner with male genotype and 1 endothelial cell in the bottom-left corner with female genotype. Cytospin and fixation procedure causes some distortion of cell morphology and loss of cytoplasm. There was no morphologic difference between donorgenotype and recipient-genotype endothelial cells. over the same time period. Thus it is clear that most CEC in fresh blood are from the recipient, whereas most of the endothelial outgrowth is from a transplantable, donor-derived cell.

The most interesting interpretation of these observations is that the recipient-derived CEC found in fresh blood are derived from vessel walls, and the delayed but exuberant outgrowth of donor-type endothelial cells in culture stems from circulating angioblasts. We hypothesize that this is the case, but definitive proof will require development of 2 new technologies. First, a new marker is needed that would allow angioblasts to be identified and distinguished from mature endothelial cells. Currently, Flk-1, Tie, Tek, and CD34 are thought to be present on hematopoietic precursors and hemangioblasts (25-27), as well as differentiated endothelial cells (1). Second, single-cell culture techniques for endothelial cells must be developed so that we could characterize a single starting cell and its specific progeny. Only when these methods are developed will a number of interesting questions become answerable definitively.

Several considerations bear on the likelihood that this hypothesis is correct. Regarding the origin of the CEC seen in peripheral blood, these, in theory, could be derived from blood vessel walls, a marrow-based progenitor, or possibly even mature endothelial cells in marrow that had not yet become incorporated into a vessel wall. If CEC were derived from either of the 2 marrowbased sources, we would expect that CEC would have the donor's genotype after successful marrow transplantation. We did not observe this. Rather, we found that almost all CEC in fresh blood had the genotype of the recipient. Therefore, these recipient-genotype CEC have only 2 possible origins: from the recipient's own vessel walls, including sinusoidal circulations such as spleen, or marrow space blood vessels that might be unaffected by the transplant, or from a substantial amount of residual functioning recipient marrow after transplant. In fact, our studies were done at a time when all marrow and blood sampling on these patients were $100 \%$ donor genotype by RFLP and/or cytogenetic analysis. Thus, derivation from residual functioning recipient marrow is very unlikely. It is most probable that recipient-genotype CEC in fresh blood truly are derived from a nonmarrow source such as the vessel wall.

On the other hand, the origin of the smaller number of circulating donor-genotype cells that display endothelial markers is less certain. It seems unlikely that they would be derived from vessel walls, because this would imply that marrow transplantation had replaced existing vessel wall endothelium. Although an interesting possibility, this seems unlikely given the exceptionally slow turnover rate of vessel wall endothelium (1) and the short time between transplant and study. Whether or not these few circulating donorderived cells with endothelial markers are actually transplanted endothelial precursor cells cannot be answered until the new technologies are developed. 


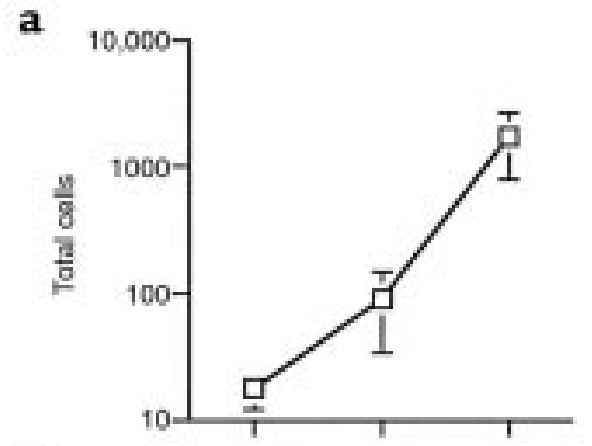

b

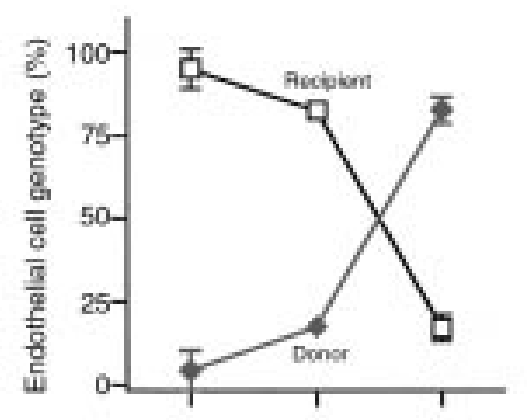

c

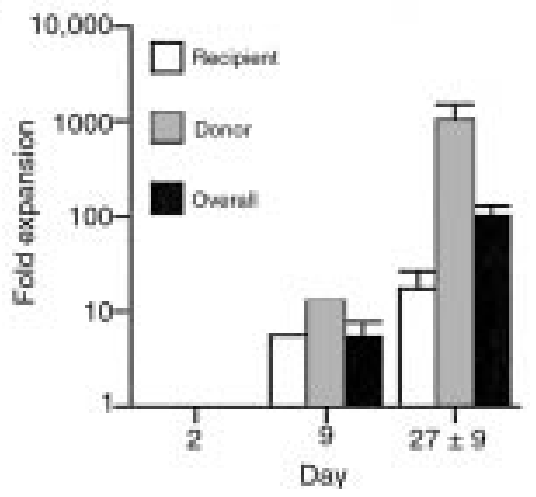

Figure 5

Endothelial outgrowth from peripheral blood of gender-mismatched bone marrow transplant recipients showing: (a) the total number of cells in culture at the 3 time points (mean \pm SD; $n=4$ ); (b) the percentage of cells at the 3 time points having recipient or donor genotype; (c) the overall fold expansion, as well as the fold expansion of cells of the 2 separate genotypes. $(n=4$, mean \pm SD for day 0 and 27 $\pm 4 ; n=2$, mean for day 9.)

The most difficult question pertains to the cell from which outgrowth cells are derived during culture. In considering this, it is important to distinguish between the outgrowth cells themselves (which we did analyze) and the cell of true interest, the starting cell(s) from which outgrowth cells are derived (which we could not analyze for the reasons given earlier). We observed that cultures of peripheral blood yield outgrowth of endothelial cells that are clearly of 2 sources: donor tissue and recipient tissue. Without single-cell culture methods, we cannot know for sure if the originating cell(s) were the recognizable donor- and recipient-genotype cells having endothelial markers that were found in fresh blood or were some other circulating cell(s) invisible to our endothelial markers. In either case, however, the source cell that results in donor-genotype outgrowth must have been acquired through the transplantation. Because our study subjects included one whose transplant was in the form of stem cells harvested from peripheral blood, this obviates concern that we have simply observed the outcome of transplanted marrows that were contaminated with marrow stromal cells.

The difference we observed between donor-genotype and recipient-genotype outgrowth endothelial cells was in their growth rate in vitro. Although the recipientgenotype CEC were present in much higher number ( $95 \%$ of CEC) in peripheral blood, recipient-genotype endothelial outgrowth was slow and reached only a 17fold expansion after a month in culture. In striking contrast, the donor-genotype CEC were present in much smaller number ( $5 \%$ of CEC) in blood, yet donorgenotype endothelial outgrowth reached 1023-fold expansion during the same month in culture. Regardless of genotype, outgrowth cells had the phenotype of quiescent microvascular endothelial cells, so both genotype cells were expanding in a culture medium optimized for microvascular endothelial growth (23). Therefore, it is likely that inherent differences in the relevant starting cells underlie this observed difference in outgrowth rate between cells of the 2 genotypes. Perhaps this would be the expected outcome of comparing outgrowth rate from mature, differentiated endothelial cells with that from angioblasts.

However, a number of uncertainties prevent a definitive conclusion in this regard. It cannot be known whether the outgrowth differences derive from the presumed inherent difference between angioblasts and mature endothelial cells or from other variables related to the transplantation: previous procedures or medications, age of cell donor, cell cycle status, etc. Our subjects were healthy and without graft-versus-host disease. We obtained identical results regardless of the following variables: (a) the time interval between transplantation and study; (b) whether paired donor and recipient ages were virtually identical or substantially different; and (c) donor age, which varied from 15 to 50 years. Cell cycle status of the relevant cells at the start of culture is not known, but we would expect that any differences in this regard would not have a large impact on culture outcome once cultures began to grow and were allowed to so do for a full month. Thus, it seems most likely that differences in endothelial outgrowth rates reflect the inherent biology of the originating cell, rather than extraneous influences.

Therefore, we can say with certainty that marrow transplantation transfers cells that circulate in the blood and can yield endothelial outgrowth. Whether or not this represents transfer of true angioblasts cannot be known with complete assurance at this time, but this seems to be a likely explanation. It is relevant that marrow-derived endothelial cells, marked by their expression of $\beta$-galactosidase regulated by an endothelial-specific promoter, tie-2, have been reported to incorporate into new vessels formed in a murine 
ischemic limb model (28). In addition, in a dog transplant model, Shi et al. (21) observed coating of vascular grafts by circulating marrow-derived cells that were CD34+ and had endothelial-like morphology, but unfortunately were not characterized otherwise. These 2 reports are consistent with our hypothesis.

Identification of the origins of CEC and blood endothelial outgrowth may facilitate the use of these cells in clinical diagnosis and biomedical applications. Indeed, there are already indications that endothelial cells or endothelial progenitors in circulation can home in to sites of ischemia $(20,28)$ and may play a role in formation of nonthrombotic neointima and angiogenesis on vascular prosthetic surfaces in vivo $(21$, 29-30). The fact that exuberant endothelial outgrowth can be achieved from peripheral blood predicts that these outgrowth cells may be an excellent autologous biomaterial source for vascular grafts and device coatings, as well as for gene therapy (31). In addition, the comparative study of CEC and endothelial outgrowth from blood should provide valuable insights into stem cell and endothelial cell biology.

\section{Acknowledgments}

We thank Judy Enenstein and Kalpna Gupta for their advice and Angela Holzer and Stanley Erlandsen for transmission electron microscopy work. This work was supported by NIH grants HL-30160 and HL-55174.

1. Cines, D.B., et al. 1998. Endothelial cells in physiology and in the pathophysiology of vascular disorders. Blood. 91:3527-3561.

2. Dejana, E., Gorada, M., and Lampugnani, M.G. 1995. Endothelial cellto-cell junctions. FASEB J. 9:910-918.

3. Edgington, T. 1995. Vascular biology: integrated molecular cell biology. FASEB J. 9:841-842.

4. Rodgers, GM. 1998. Hemostatis properties of normal and perturbed vascular cells. FASEB J. 2:116-123.

5. Pool, E.H., and Dunlop, G.R. 1934. Cancer cells in the blood stream. Am. J. Cancer. 21:99-103.

6. Hladovec, J., and Rossman, P. 1973. Circulating endothelial cells isolated together with platelets and the experimental modification of their counts in rats. Thromb. Res. 3:665-674.

7. George, F., et al. 1991. Cytofluorometric detection of human endothelial cells in whole blood using S-Endo 1 monoclonal antibody. $J$. Immunol. Methods. 139:65-75.

8. Sbarbati, R., et al. 1991. Immunologic detection of endothelial cells in human whole blood. Blood. 77:764-769.

9. Solovey, A., et al. 1997. Circulating activated endothelial cells in sickle cell anemia. N. Engl. J. Med. 337:1584-1590 .

10. Bouvier, C.A., Gaynor, E., Cintron, J.R., Bernhardt, B., and Spaet, T.H. 1970. Circulating endothelium as an indication of vascular injury.
Thromb. Diath. Haemorrh. 40(Suppl.):163-168.

11. Hladovec, J., Prerovsky, I., Stanek, V., and Fabian, J. 1978. Circulating endothelial cells in acute myocardial infarction and angina pectoris. Klin. Wochenschr. 56:1033-1036.

12. Sowemimo-Coker, S.O., Meiselman, H.J., and Francis, R.B., Jr. 1989. Increased circulating endothelial cells in sickle cell crisis. Am. J. Hematol. 31:263-265.

13. Drancourt, M., George, F., Brouqui, P., Sampol, J., and Raoult, D. 1992. Diagnosis of Mediterranean spotted fever by indirect immunofluorescence of Rickettsia conorii in circulating endothelial cells isolated with monoclonal antibody-coated immunomagnetic beads. J. Infect. Dis. 166:660-663.

14. Lefevre, P. 1993. Detection of circulating endothelial cells in thrombotic thrombocytopenic purpura. Thromb. Haemost. 69:522.

15. Grefte, A., van der Giessen, M., van Son, W., and The, T.H. 1993. Circulating cytomegalovirus-infected endothelial cells in patients with an active CMV infection. J. Infect. Dis. 167:270-277.

16. George, F., et al. 1993. Demonstration of Rickettsia conorii-induced endothelial injury in vivo by measuring circulating endothelial cell, thrombomodulin, and von Willebrand factor in patients with Mediterranean spotted fever. Blood. 82:2109-2116.

17. Percivalle, E., Revello, M.G., Vago, L., Morini, F., and Gerna, G. 1993. Circulating endothelial giant cells permissive for human cytomegalovirus (HCMV) are detected in disseminated HCMV infections with organ involvement. J. Clin. Invest. 92:663-670.

18. Solovey, A., Gui, L., Key, N.S., and Hebbel, R.P. 1998. Tissue factor expression by endothelial cells in sickle cell anemia. J. Clin. Invest. 101:1899-1904.

19. Hebbel, R.P., Solovey, A., Solovey, A. 1999. Circulating endothelial cells have the same activation phenotype as vessel wall endothelium in sickle transgenic mice. FASEB J. 13:1118a. (Abstr.)

20. Asahara, T., et al. 1997. Isolation of putative progenitor endothelial cells for angiogenesis. Science. 275:964-967.

21. Shi, Q., et al. 1998. Evidence for circulating bone marrow-derived endothelial cells. Blood. 92:362-367.

22. Davison, P.M., Bensch, K., and Karasek, M.A. 1980. Isolation and growth of endothelial cells from the microvessels of the newborn human foreskin in cell culture. J. Invest. Dermatol. 75:316-321.

23. Gupta, K., Ramakrishnan S., Browne, PV., Solovey, A., and Hebbel, R.P. 1997. A novel technique for culture of human dermal microvascular endothelial cells under either serum-free or serum-supplemented conditions: isolation by panning and stimulation with vascular endothelial growth factor. Exp. Cell Res. 230:244-251.

24. Swerlick, R.A., Lee, K.H., Wick, T.M., and Lawley, T.J. 1992. Human dermal microvascular endothelial but not human umbilical vein endothelial cells express CD36 in vivo and in vitro. J. Immunol. 148:78-83.

25. Fina, L., et al. 1990. Expression of the CD34 gene in vascular endothelial cells. Blood. 75:2417-2426.

26. Kabrun, N., et al. 1997. Flk-1 expression defines a population of early embryonic hematopoietic precursors. Development. 124:2039-2048.

27. Risau, W. 1995. Differentiation of endothelium. FASEB J. 9:926-933.

28. Takahashi, T., et al. 1999. Ischemia- and cytokine-induced mobilization of bone marrow-derived endothelial progenitor cells for neovascularization. Nat. Med. 5:434-438.

29. Scott, S.M., Barth, M.G., Gaddy, L.R., and Ahl, E.T. 1994. The role of circulating cells in the healing of vascular prostheses. J. Vasc. Surg. 19:585-593.

30. Rafii, S., et al. 1995. Characterization of hematopoietic cells arising on the textured surface of left ventricular assist devices. Ann. Thorac. Surg. 60:1627-1632.

31. Mulligan, R.C. 1993. The basic science of gene therapy. Science 260:926-931. 